\title{
Social Participation of People with Intellectual Disabilities in Rural Areas of the Philippines
}

\author{
Akira Teramura $^{1,2}$, Kosuke Hamada $^{2,3}$, Seiji Yamamoto ${ }^{1,4}$ \\ ${ }^{1}$ Osaka Health Science University \\ ${ }^{2}$ Graduate School of Human Sciences, Osaka University \\ ${ }^{3}$ Aichi Medical College for Physical and Occupational Therapy \\ ${ }^{4}$ Graduate School of Health Sciences Department of Public Health, Kobe University
}

\begin{abstract}
The purpose of this study was to analyze the current status and challenges related to social participation faced by people with intellectual disabilities living in rural areas in the Philippines. Semi-structured interviews were conducted with 10 professionals, including nurses of public health center, social workers of nonprofit facility for persons with disabilities, and teachers of public and private special needs schools. The study was approved by the Graduate School of Human Sciences, Osaka University. The results indicated five categories and 21 subcategories. The five categories are: Current status of social participation of people with intellectual disabilities in rural areas; Interventions performed by rural professionals for people with intellectual disabilities; Improved activities of people with intellectual disabilities owing to study participants' interventions; Recognition of hindrances to promote social participation; Recognition of the ideal social participation for people with intellectual disabilities. Based on the current conditions, there were challenges in leisure activities and employment, especially for adults with intellectual disabilities. Our findings suggest it is important for Philippine occupational therapists and those working in international organizations to conduct occupation analysis for understanding the backgrounds, strengths, limitations, concerns, and goals for their leisure activities and employment. In addition, occupational therapists can contribute not only to providing individual support but also to the development of community supporters.
\end{abstract}

Keywords: Philippines, Rural, Intellectual Disability, Social Participation

(Asian J Occup Ther 17: 83-89, 2021)

\section{Introduction}

In September 2015, the Sustainable Development Goals (SDGs) were adopted by the United Nations General Assembly. They were based on the concept of "no one will be left behind," meaning no one will be left vulnerable to society, including persons with disabilities. Previous research has already clearly delineated the issues faced by persons with disabilities, such as access to medical care, education, employment, and community development, as well as the importance of their social participation [1]. According to the World Report on Dis-

Received: 31 May 2020, Accepted: 30 May 2021

Corresponding to: Akira Teramura, Osaka Health Science University, 1-9-27 Tenman, Kita-ku, Osaka-shi, Osaka 530-0043 Japan

e-mail: u402964b@ecs.osaka-u.ac.jp

(C2021 Japanese Association of Occupational Therapists ability published in 2011 by the World Health Organization and the World Bank, the number of persons with disabilities accounts for $15 \%$ of the world population, of which about $80 \%$ live in developing countries [2]. Many persons with disabilities face poverty because of the barriers imposed upon their access to social participation in a wide variety of fields (e.g., education, health, and employment) [3]. Particularly, persons with disabilities living in rural areas of developing countries tend to be excluded from society [4], and experience great differences in various aspects of their lives compared to those living in urban areas. For example, people with disabilities living in rural areas have fewer opportunities for medical services including rehabilitation, education, and employment than people with disabilities living in urban areas. Moreover, it is not easy to use public transportation in rural areas [2-4].

Furthermore, only $0.1-0.4 \%$ of people with intellec- 
tual disabilities (PID) living in developing countries can receive appropriate public services [5]. PID living in developing countries do not receive appropriate support for social participation compared to those in developed countries $[2,6]$. Due to these current conditions, many PID are not able to work, which often leads to poverty [2-4].

The Japanese government created a support project called the Japan International Cooperation Agency (JICA). For over 60 years, JICA has assisted people with disabilities living in developing countries by managing the work of medical welfare workers who attend to these populations. JICA has achieved this by dispatching volunteers to support occupational therapists and conducting financial cooperation projects. In the past, many of JICA's projects aimed at supporting PID in targeted urban areas $[5,6]$. Recently, there has been an increase in the number of projects targeting rural areas [6]. For example, JICA has implemented barrierfree development in many countries such as Bolivia, India, Vietnam, and Senegal. However, persons with physical disabilities are the main targets of most of these rural projects, and there are few rural programs targeted at improving the social participation of PID [7].

In 2018, the first author investigated a welfare facility in rural areas of Bohol, the Philippines, to examine the progress - and current status - of the activities for Filipino adults with intellectual disabilities. However, the content was limited to activities within only one facility, and the relationship between professional interventions and social participation was not clarified. Further, the details of the interventions of specialists in multiple facilities in rural areas, especially in the medical, welfare, and education fields, were unclear [8].

To the best of our knowledge, there is no comprehensive study on the current status of support for PID living in rural areas of the Philippines. Therefore, this study aimed to interview workers engaged in providing medical, welfare, and educational support for PID living in rural areas of Bohol, the Philippines. Particularly, we aimed to examine the support that this vulnerable population is currently receiving, as well as their current levels of social participation. Moreover, we aimed to clarify the benefits of occupational therapists in rural areas of developing countries working with other specialists in the same settings. This type of cooperation could make occupational therapy intervention more useful by better understanding the interventions of other experts and the social participation of PID.

This study is significant because it seeks to contribute to the promotion of social participation of PID living in rural areas of developing countries; hence, we propose methods on this subject based on occupational therapists' expertise.

\section{Methods}

\section{Research Participants}

Participants were 10 professionals - nurses of public health center, social workers of nonprofit facility for persons with disabilities, teachers of public and private special needs schools, and teachers of private special needs schools in rural areas of Bohol. We utilized snowball sampling method by procuring an introduction from a director of a welfare facility having previous experience with our work. Given the purpose of this study, participants were required to know both disability characteristics and regional characteristics.

\section{Data Collection}

We visited each facility and conducted semi-structured interviews in English between August 1 and 9, 2019. We asked participants about their basic information - gender, age, facility, specialty, years of experience in supporting persons with disabilities, and years of experience in supporting PID. Then, we conducted the interviews based on four guiding topics: (1) Social participation of PID: "How do PID spend their time at home or in the community?" (2) Interventions aimed at PID: "What kind of interventions do you apply for PID?" (3) Difficulties in social participation: "What are the difficulties that PID experience when trying to participate in society?" (4) Specific methods aimed at enhancing the social participation of PID: "What kind of intervention are you considering to further their social participation?"

The interviews were conducted based on the outlined interview guide, but we also listened to participants' narratives outside of the interview questions and took all measures to respect their answers and descriptions regarding each of the four major topics. After each participant provided written consent, we recorded each interview through an IC chip recorder.

\section{Data Analysis}

We conducted qualitative analyses based on M-GTA (Modified Grounded Theory Approach) [9, 10], which was considered suitable, because its theoretical groundings relate to the social participation construct, are relevant for analyses in the intellectual disability context, and are excellent in explaining and predicting human behavior.

First, a verbatim transcript was created from raw interview data. Participants' narrative contents were simplified into single sentences that denoted the general idea of the content of a phrase, and were subsequently coded, while maintaining the meaning of the expressed phrase/word. We generated analytical concepts that 
Table 1 Profile Characteristics of Participants

\begin{tabular}{|c|c|c|c|c|c|c|c|}
\hline № & Gender & $\begin{array}{c}\text { Age } \\
\text { (years) }\end{array}$ & Affiliation & Professional & $\begin{array}{l}\text { Period for PWDs } \\
\text { (years) }\end{array}$ & $\begin{array}{l}\text { Period for PIDs } \\
\text { (years) }\end{array}$ & $\begin{array}{l}\text { Interview Time } \\
\text { (min) }\end{array}$ \\
\hline 1 & Female & $20 \mathrm{~s}$ & Public Health Center & Nurse & 8 & 3 & 47 \\
\hline 2 & Female & $20 \mathrm{~s}$ & Public Health Center & Nurse & 9 & 5 & 52 \\
\hline 3 & Female & $30 \mathrm{~s}$ & Public Health Center & Nurse & 17 & 11 & 37 \\
\hline 4 & Female & $40 \mathrm{~s}$ & Welfare Facility & Social Worker & 20 & 12 & 88 \\
\hline 5 & Female & $50 \mathrm{~s}$ & Welfare Facility & Social Worker & 25 & 20 & 45 \\
\hline 6 & Female & $50 \mathrm{~s}$ & Public Special School & Teacher & 25 & 10 & 85 \\
\hline 7 & Female & $40 \mathrm{~s}$ & Public Special School & Teacher & 23 & 15 & 55 \\
\hline 8 & Female & $20 \mathrm{~s}$ & Public Special School & Teacher & 5 & 3 & 49 \\
\hline 9 & Male & $30 \mathrm{~s}$ & Private Special School & Teacher & 15 & 10 & 39 \\
\hline 10 & Male & $20 \mathrm{~s}$ & Private Special School & Teacher & 6 & 6 & 44 \\
\hline
\end{tabular}

PWD: People with Disability

$15.3 \pm 7.4$

PID: People with Intellectual Disability

explained the proposed codes and conducted continuous comparative analysis by focusing on the context of the narratives, which were strongly related to the social participation of PID. Next, we formed categories based on the relationships between the generated codes. During these procedures relevant to generating analytical concepts, we discussed the proposed classifications until we found no possible theoretical objections regarding the proposed classifications.

Based on the categories and subcategories created by the aforementioned procedures, we structurally organized the current situation of the social participation of PID living in rural areas of Bohol and examined the problems regarding the topic. We highlight that one of the researchers had already engaged in international medical and health research (SY) and was well versed with the subject matter. Moreover, multiple researchers engaged in international medical and health research with different theoretical and methodological backgrounds ( $\mathrm{KH}$ and $\mathrm{MK}$ ) participated in this study. To ensure the study's credibility, all researchers jointly conducted triangulation procedures.

\section{Ethical Considerations}

This study followed the ethical standards of the Declaration of Helsinki exactly, and was performed with the approval of the ethics review committee of the Graduate School of Human Sciences, Osaka University. Prior to participation, we explained - both verbally and on paper - the study aims and procedures to the participants and obtained their written consent.

\section{Results}

\section{Participants' Characteristics}

Our sample comprised 2 male and 8 female participants (average age $=37.2 \pm 10.2$ years). Their average number of years of experience in supporting persons with disabilities was $15.3 \pm 7.4$ years, and average number of years of experience in supporting PID was 9.5 \pm 5.3 years. There were 3 nurses, 2 social workers and 5 teachers. The average interview time for each research participant was $54.1 \pm 17.7$ minutes (Table 1).

\section{Social Participation and Issues of PID Living in Rural Areas}

In total, we extracted 464 codes related to the current state of social participation, support contents, and the issues of PID living in rural areas of Bohol, the Philippines. We categorized codes based on those that had similar meanings and expressions and made efforts to constantly return to the context of the specific codes in the participants' narratives, to ensure that each code was accurately categorized. In total, we obtained 5 categories and 21 subcategories (Table 2).

The subcategories that make up each category are described in Table 2. To facilitate differentiation between the categories, subcategories, and raw data in the text, we utilized the following symbols: 【 $】=$ a category, [ ] = a sub-category, and " " = raw data.

In the category 【Current status of social participation of PID in rural areas】, the following example narratives from participants provide context to the results. One participant provided a statement related to the subcategory [People with mild intellectual disabilities have roles in the home and in the community]: "Adults with intellectual disabilities can help cook at home and play basketball with local residents." Another study participant provided a statement related to the subcategory [PID have few opportunities to interact with local residents]: "PID have little interaction with others because they cannot speak at the same language level as do their families and community residents, and they are not good at communicating." One study participant 
Table 2 Social participation of people with intellectual disabilities through the recognition of rural professionals

\begin{tabular}{|c|c|}
\hline Category (Code quantity) & Sub category (Code quantity) \\
\hline $\begin{array}{l}\text { Current status of social participation } \\
\text { of people with intellectual disabilities } \\
\text { in rural areas (141) }\end{array}$ & $\begin{array}{l}\text { People with mild intellectual disabilities have roles in the home and in the community (21) } \\
\text { People with intellectual disabilities have few opportunities to interact with local residents (33) } \\
\text { People with intellectual disabilities have restrictions on home activities (35) } \\
\text { People with intellectual disabilities have restrictions on community activities (39) } \\
\text { People with intellectual disabilities tend to be treated unfairly by local residents (13) }\end{array}$ \\
\hline $\begin{array}{l}\text { Interventions performed by rural } \\
\text { professionals for people with } \\
\text { intellectual disabilities (81) }\end{array}$ & $\begin{array}{l}\text { Professionals provide medical examinations and family guidance on how to treat infants (10) } \\
\text { Professionals provide learning guidance and emotional education programs (34) } \\
\text { Professionals provide few vocational training programs (14) } \\
\text { Professionals provide opportunities for people with intellectual disability to interact with local } \\
\text { residents (23) }\end{array}$ \\
\hline $\begin{array}{l}\text { Improved activities of people with } \\
\text { intellectual disabilities owing to study } \\
\text { participants' interventions (56) }\end{array}$ & $\begin{array}{l}\text { People with intellectual disabilities have more activities to do at home (10) } \\
\text { People with intellectual disabilities have become more actively engaged in institutional programs (14) } \\
\text { People with intellectual disabilities have mutual peer assistance, and relationships have been built (22) } \\
\text { People with intellectual disabilities have more opportunities to interact with local residents (10) }\end{array}$ \\
\hline $\begin{array}{l}\text { Recognition of hindrances to promote } \\
\text { social participation (115) }\end{array}$ & $\begin{array}{l}\text { People with intellectual disabilities cannot receive continuous medical services (9) } \\
\text { People with intellectual disabilities cannot receive education and welfare services owing to } \\
\text { accessibility issues (20) } \\
\text { People with intellectual disabilities cannot work (58) } \\
\text { Local residents sometimes do not comply with the legal system for intellectual disabilities (9) } \\
\text { Local residents have prejudice and discrimination against people with intellectual disabilities (19) }\end{array}$ \\
\hline $\begin{array}{l}\text { Recognition of the ideal social } \\
\text { participation for people with } \\
\text { intellectual disabilities ( } 71)\end{array}$ & $\begin{array}{l}\text { People with intellectual disabilities need to increase their leisure activities (20) } \\
\text { People with intellectual disabilities can earn money (37) } \\
\text { People with intellectual disabilities can make their own decisions (14) }\end{array}$ \\
\hline
\end{tabular}

provided a comment related to the subcategory [PID have restrictions on home activities]: "PID are unable to help with housework, and they do nothing at home." One study participant provided a comment related to the subcategory [PID have restrictions on community activities]: "PID cannot perform leisure activities outside their home." Lastly, a study participant provided a statement that related to the subcategory [PID tend to be treated unfairly by local residents]: "Children with disabilities may be bullied and women with intellectual disabilities may be raped."

Regarding the category 【Interventions performed by rural professionals for PID], one study participant provided a statement related to the subcategory [professionals provide medical examinations and family guidance on how to treat infants]: "We carry out simple medical examinations and family instructions several times." Another participant provided a statement related to the subcategory [professionals provide learning guidance and emotional education programs]: "I teach language, calculation, music, etc. at a special needs school." Moreover, one research participant provided a comment related to the subcategory [professionals provide vocational training programs]: "We provide PID the opportunity to experience cooking, crafting, agriculture, and selling goods at welfare facilities." Finally, a par- ticipant provided a statement regarding the subcategory [professionals provide opportunities for PID to interact with local residents]: "We encourage participants to participate in events such as local sports competitions through the organization."

The category 【Improved activities of PID owing to study participants' interventions】 also included many narratives. One research participant provided a comment related to the subcategory [PID have more activities to do at home]: "PID have started to care for their homes by cleaning their desks and cooking rice." Another participant said about the subcategory [PID have become more actively engaged in institutional programs]: "PID began to calculate the values of their products while selling goods and worked with agriculture." Furthermore, a participant provided a statement related to the subcategory [PID have mutual peer assistance, and relationships have been built]: "PID started to help each other with tasks they are not good at." Another participant provided a comment related to the subcategory [PID have more opportunities to interact with local residents]: "PID have been invited by residents to participate in religious festivals and volleyball competitions held in the district."

In the category 【Recognition of hindrances to promote social participation】 a participant provided a comment related to the subcategory [PID cannot receive 
continuous medical services]: "In private clinics, medical costs are high, so PID cannot access these services." Another provided a statement related to the subcategory [PID cannot receive education and welfare services owing to accessibility issues]: "Children with severe intellectual disabilities and adults with intellectual disabilities cannot frequently attend schools and facilities because they are located far away." Additionally, a participant provided a statement regarding the subcategory [PID cannot work]: "There are few places in the area that provide vocational training, such as workshops. Further, there are few professionals who provide employment support." Another participant said about the subcategory [Local residents sometimes do not comply with the legal system for intellectual disabilities]: "The law that regulates discounts for persons with disabilities to access entertainment facilities is not fully enforced in the area." Concluding this category, a participant commented about the subcategory [Local residents have prejudice and discrimination against PID]: "The prejudice and discrimination of local residents is strong, and the behaviors of PID are not understood."

Coming to the category 【Recognition of the ideal social participation for PID], a participant provided a statement related to the subcategory [PID need to increase their leisure activities]: "PID should continue to have opportunities to interact with local residents at local events." Another participant remarked about the subcategory [PID can earn money]: "PID can do many rural jobs, such as agriculture and fishing, in a short period of time." Finally, a participant said about the subcategory [PID can make their own decisions]: "Even if family members and professional supporters provide assistance, PID can still make their own decisions."

\section{Discussion}

In this study, participants reported that some people with mild intellectual disabilities who lived in rural areas of Bohol, the Philippines were involved in local sports and employment. However, most had few opportunities to interact with other local residents, experienced limited activities, and were mistreated by some residents within the local community. Participants reported that community health centers, welfare facilities, and special needs schools provided PID simple medical services, educational and employment support, and encouragement to participate in community activities. Owing to such institutions, PID in this setting seem to be currently experiencing improvements regarding the number of opportunities available to perform different types of activities and to experience interpersonal exchanges. However, some barriers to the promotion of social par- ticipation among this population remain; for example, difficulty in providing continuous medical services, travelling/access problems (owing to the distance from their homes to the institutions and facilities in which the activities are performed), difficulty finding work opportunities, and local residents' lack of understanding about the behaviors and characteristics of PID.

The category 【Current situation of social participation of PID in rural areas】 comprised topics regarding the lack of opportunities for PID to experience interpersonal exchanges, the unfair treatment they receive from local residents, and restrictions on the activities available to them both inside and outside their homes.

Owing to their disability characteristics, PID experience a deficit in abstract thinking and judgment, as well as in planning and problem-solving skills [11]. Additionally, people without disabilities tend to have a harder time understanding PID than those with physical disabilities, and the former are more likely to experience discrimination and prejudice than the latter $[12,13]$. Furthermore, the provision and accessibility of social resources are weaker in rural areas than in urban areas [2]. Convention on the Rights of Persons with Disabilities that the United Nations General Assembly was drafted in 2006, and the Philippines ratified in 2008 [14]. Our study participants recognized that there is a tendency for equal opportunities and participation to be impeded, especially among those with moderate to severe intellectual disabilities.

Additionally, the categories 【Interventions performed by rural professionals supporters for PID】 and 【Improved activities of PID owing to study participants' interventions】comprised topics related to specialized professional interventions in the fields of medical care, welfare, and education by the study sample. The main interventions provided by the professionals related to simple examinations regarding patients' intellectual functions, and family guidance for infants who were in medical institutions-mostly public health facilities, where costs are low. Private medical institutions also provide services but are not preferred as they are expensive. Another concern is the inability to access these services regularly after school age. Moreover, educational institutions provided support for children with disabilities throughout school years; the contents comprised math, language (learning the alphabet), and music activities. Additionally, welfare facilities provided opportunities for this populational group to have access to different daily and community activities. After using the services provided by these facilities, our participants reported that the PID they interacted with started being able to assist in the cooking and cleaning chores at their homes and being able to actively carry out activities 
such as making crafts (wood and paper craft) and caring for pets (such as dogs and cats or livestock such as chickens and ducks) in the facility. Furthermore, those frequenting the facility also started to engage in activities to help each other with their intellectual disabilities, and to participate in sports competitions with local residents, all of which increased their opportunities to engage in interpersonal interactions. Nonetheless, although the Convention on the Rights of Persons with Disabilities requires participating countries to ensure that rehabilitation services are provided for this public [14], our results showed that the welfare institutions had only few rehabilitation specialists. Hence, PID living in rural areas of Bohol still need individual and group interventions that evaluate their intellectual functioning and social adaptation and consider their culture and environment.

Regarding the category 【Recognition of hindrances to promote social participation】, our participants recognized that PID were not able to receive continuous medical services or access education and welfare services owing to transport accessibility issues, such as their inability to board the local buses and pay the fare, and the lack of available buses to reach the far-off facilities. Moreover, they faced difficulties in finding work. The interviewed supporters also felt that local residents had prejudice against PID, so the residents often did not comply with the legal system for PID.

Although there is an employment support program that is promoted by a public rehabilitation center in the Philippines, it is implemented mainly in urban areas [15]. Therefore, employment support initiatives for PID in the region are limited to some disability support groups and special support schools. In order to enhance the employment opportunities of PID living in rural areas of the Philippines, a project that specializes in employment support for this public should be implemented. Particularly, stakeholders should engage with not only one institution but also promote a strategic cooperation with professionals and a wider array of institutions and companies, both public and private.

Regarding the category 【Recognition of the ideal social participation for PID】, participants recognized that persons with disabilities should ideally participate in leisure activities, be able to work, and earn their incomes. However, participants were not able to provide specific methods regarding the promotion of such ideal social participation and were not able to outline how to develop interventions that are tailored to the disability and environment characteristics that surround this populational group.

To promote the social participation of people with disabilities living in developing countries, World Health
Organization recommends the concept of Community-Based Rehabilitation (CBR), which is used worldwide [16]. CBR comprises five components: Health, Education, Livelihood, Social, and Empowerment. It is aimed at developing the entire community and is not just an intervention for the recovery of functional disabilities. Additionally, in CBR, occupational therapists are also expected to participate for the purpose of social participation in supporting people with disabilities in developing countries [17]. The results of this research indicate that the development of employment and leisure activities in adulthood is essential for the ideal social participation of PID. Occupational Therapy Association of the Philippines has also stated the need for OT intervention for adults with intellectual disabilities in rural areas [18]. These findings suggest the need for OT in the study area. To promote their leisure activities, occupational therapists use occupational analysis to match an individual's abilities with the demands of the task [19]. In addition, occupational therapists use the concepts of COPM and ICF to assess their activities for providing effective support. Occupational therapist understands the experience background, strengths, weaknesses, worries, and goals of the person with disability and provides highly specialized interventions [17].

In CBR, occupational therapists are also expected to teach and train CBR workers and volunteers in basic assessment and interventions to help people with intellectual disabilities lead better daily lives [20]. The supporters and occupational therapists then check on the progress of the program and support the parents in their guidance and activities to diminish stigma in the community [19]. In other words, in a study area in which the number of occupational therapists is limited, it is important not only to provide individual support but to also train supporters to support the entire community. We hope that this study's findings provide guidance to occupational therapists from support groups in the Philippines and elsewhere, such as JICA and international NGOs.

\section{Limitations}

Although our study included novel qualitative results in the field of disability research, it still had methodological limitations. First, our sample size was small. Second, we performed our interviews in a very limited area of the Philippines. In the rural areas of the Philippines, the number of facilities and professionals that supported PID was very limited at the time of this study. Therefore, our study comprised only the Bohol province, making it difficult to generalize our results. Future studies should conduct interviews among PID and their 
families, other types of specialists, and other types of companies in order to plan more detail OT interventions. Moreover, we suggest future research endeavors collect data in other regions of the Philippines on the current situation and issues regarding the social participation of PID, which will contribute to a clearer understanding of the problems throughout the country on the topic and allow specific solutions and programs to be devised for each region.

\section{Conclusion}

Based on our qualitative results, many PID living in rural areas of the Philippines experience difficulties regarding social participation owing to their activity restrictions. Our study participants reported that the studied populational group lacked continuous medical services, lacked adequate access to education (owing to living in remote areas and having severe intellectual disabilities, because of which they needed to be accompanied to the distant locations to access the services), experienced difficulties in receiving employment assistance, and were not understood by local residents. We propose that international stakeholders try to collaborate with specialists in the fields of medicine, welfare, education, and occupational therapy to improve on the studied populational group's access to leisure activities and employment opportunities; such collaborations may ensure the promotion of an ideal social participation of PID living in the rural areas of the Philippines.

\section{References}

[1] United Nations. Transforming our World: The 2030 Agenda for Sustainable Development [online]. New York [cited 2020 May 1] Available from: https://sustainable development.un.org/content/documents/21252030\%20 Agenda $\% 20$ for $\% 20$ Sustainable $\% 20$ Development $\% 20$ web.pdf.

[2] World Health Organization. World Report on Disability [online]. Genevieve [cited 2020 April 13]. Available from: https://www.who.int/publications-detail/world-report-ondisability.

[3] Elwan A. Poverty and Disability: A Survey of the Literature [online]. Washington. [cited 2020 April 13] Available from: http://documents.worldbank.org/curated/en/488521 468764667300/pdf/multi-page.pdf.

[4] Mori S. Employment Law for Persons with Disabilities in the Philippines (in Japanese). In: Employment Law for Persons with Disabilities in Asia: Nondiscrimination and Employment Promotion (Ajia no shougaishakoyouhousei sabetukinnshi to koyousokushin) Chiba. Institute of Developing Economies. 2012; 157-86.

[5] Nakamura S. Support for persons with disabilities (in
Japanese). JICA's World. Japan International Cooperation Agency, 2011, No.39, 17.

[6] Japan International Cooperation Agency. Disability and Development [online]. Tokyo. [cited 2020 April 13]. Available from: https://www.jica.go.jp/activities/issues/ social_sec/ku57pq00002cyac5-att/guideline_handicap development.pdf.

[7] Takahashi Y, Ito N. Current movements and future prospects of support for people with disabilities (in Japanese) Japanese Journal of Vocational Rehabilitation. 2005; 19(1): 15-21.

[8] Teramura A. Place and local community for people with intellectual disability. Journal of Mirai Kyosei. 2020; 135-50.

[9] Kinoshita Y. Practice of Grounded Theory Approach-Invitation to Qualitative Research (in Japanese). Nagoya: Kobundo; 2003.

[10] Kambaru A. Qualitative research and a modified grounded theory approach. Tsuru University Review. 2018; 88: 47-58.

[11] Harris JC. Intellectual Disability: Understanding Its Development, Causes, Classification, Evaluation, and Treatment. Oxford: Oxford University Press; 2005.

[12] Owen F, Griffiths D, Endicott O. Challenges to the Human Rights of People with Intellectual Disabilities. London: Jessica Kingsley Publishers; 2008.

[13] Sheila B, Cruz V, Griffiths D, Owen F, Watson SL. The Human Rights Agenda for Persons With Intellectual Disabilities. New York: NADD Press; 2012.

[14] United Nations. Convention on the Rights of Persons with Disabilities and Optional Protocol [online]. New York. [cited 2020 April 13]. Available from: https://www. un.org/development/desa/disabilities/convention-on-therights-of-persons-with-disabilities.html.

[15] Nakanishi Y. People with Disability in Asia (in Japanese). Tokyo: Gendaishokan; 1996.

[16] World Health Organization. Community-based rehabilitation guidelines. Switzerland, World Health Organization. 2010.

[17] Curtin M, Mary Egan M, Adams J. Occupational Therapy for People Experiencing Illness, Injury or Impairment: Promoting occupation and participation. 7th ed. Holland: ELSEVIER; 2017; 485-507.

[18] Philippine Academy of Occupational Therapists. The Philippine Occupational Therapy Research Agenda. the Republic of the Philippines. Manila, Philippine Academy of Occupational Therapists; 2015; 2.

[19] Sakellariou D, Pollard N. Occupational Therapies Without Borders: Integrating Justice with Practice: Sakellariou D, Pollard N, editors. 2nd ed. Holland: ELSEVIER; 2016; 126-51.

[20] Lankester T, Nathan Grills N, Duncan E. Setting Up Community Health and Development Programmes in Low and Middle Income Settings, 4th ed. United Kingdom: Oxford Univ; 2019; 409-16. 